\title{
La calidad como verdadera meta
}

\author{
José Luis Crespo Fajardo \\ luis.crespo@ucuenca.edu.ec \\ Fabián Cazar Almache \\ fabian.cazar@ucuenca.edu.ec \\ Comité Editorial de ESTOA \\ Cuenca, julio de 2019
}

T ras las bambalinas, más allá de la imagen de nuestra revista, se oculta un equipo de trabajo muy preocupado en que el resultado final presente un alto nivel de calidad. Hacer las cosas bien es el objetivo de la organización interna de Estoa, centrada en gestionar los pr ocesos editoriales, observar tiempos y periodicidad, cumplir con las exigencias de autores y revisores, y ante todo tratar de ajustar mejoras significativas en cada número.

En efecto, detrás de Estoa, que ya cumple siete años de existencia, está el personal del CINA (Centro de Investigación de la Facultad de Arquitectura y Urbanismo), un organismo cada vez más comprometido con la idea de que esta revista puede suponer un aporte intangible y un reconocimiento tácito a la investigación (vista desde el otro lado del espejo) que es capaz de ejecutar la Universidad de Cuenca. Así pues, Estoa intenta constituirse como motivo de orgullo para la comunidad científica de nuestra región latinoamericana, en la medida que busca alcanzar cotas de excelencia internacional formando parte de bases de datos de relevancia. Es así que últimamente hemos logrado cumplir los exigentes requisitos editoriales precisos para entrar en SciELO -Ecuador y en el nuevo Catálogo 2.0 de Latindex, toda vez que el sistema Open Journal Sistems (OJS) de la revista se ha actualizado a la versión 3.0, y se han comenzado a trabajar los artículos con el lenguaje XML JATS (Journal Article Tag Suite). Estos avances evidencian que estamos haciendo el trabajo de modo correcto.

A nivel interno, hemos acentuado el rigor de las prerevisiones de los originales, en un intento de lograr un valioso perfeccionamiento de lo que finalmente llega a publicar la revista. Asimismo, los tiempos de respuesta a los autores y el seguimiento que estos pueden hacer de sus artículos se han optimizado en tanto todo el proceso de gestión editorial ha pasado a realizarse completamente a través de la plataforma OJS.

En lo referente a las evaluaciones, tras una razonada reestructuración nos hemos quedado en exclusiva con una participativa base de colaboradores internacionales con nivel de doctorado, estudiosos de sobrado prestigio académico procedentes de algunas de las principales universidades del mundo. También fue reestructurado el consejo científico de nuestro equipo editorial, integrado ahora por una serie de investigadores en activo de gran relevancia, lo cual es confirmado por sus números en el indicador $\mathrm{H}$ Index de Scopus.

A través de diferentes estrategias de difusión, hemos logrado que la tasa de recepción de artículos se haya incrementado notablemente, lo cual es un éxito para una revista que es ciento por ciento universitaria, y no sigue ningún modelo de lucro. Ciertamente, nuestra filosofía es que, en última instancia, todo proceso de evaluación se realiza para beneficio de la sociedad, puesto que examinar la calidad de un artículo es buscar enriquecerlo y que se convierta, finalmente, en un mejor aporte para la ciencia. Estoa nace así del generoso esfuerzo de los que, en cada una de las partes del proceso editorial, se implican con total dedicación y consciencia de la importancia de aquello que se trae a la luz de la comunidad científica.

Nos quedan aún muchas facetas por mejorar, si bien constantemente atendemos a las novedades y buenas prácticas que surgen en el universo de las revistas científicas, en especial en las de nuestro ramo. Hoy dirigimos todos los esfuerzos a lograr un buen posicionamiento como revista de referencia en el ámbito de la arquitectura y el urbanismo en lengua española, pero para ello, por encima de las estadísticas, las indexaciones y la capacidad de difusión, queremos anteponer los estándares de calidad. Los índices bibliométricos pueden ser engañosos y las cifras pueden ser alteradas, pero la calidad del contenido de un artículo supone un fundamento que, a nuestro modo de ver, solamente la crítica de la historia podría juzgar. Qué duda cabe, por consiguiente, de que la calidad debe ser siempre la verdadera meta. 